\section{Korkeakoululaitoksen kehityshistoria vailla yhteiskuntakehityksen teoriaa}

Välimaa, Jussi (2018). Opinteillä oppineita. Suomalainen korkeakoulutus keskiajalta 2000-luvulle. Kuopio: University Press of Eastern Finland UPEF. 387 sivua.

KOULUTUKSEN tutkimuslaitoksen johtaja Jussi Välimaa luo Opinteillä oppineita -teoksellaan suomalaiskansallisen katseen korkeakoululaitoksen kehitykseen. Tekijä näkee työnsä käsikirjana, aiempaa tutkimusta kokoavana yleisesityksenä ja uuttakin tutkimusta tarjoavana yliopistollisena oppikirjana.

Käsikirjan yleisöä ajatellen teokseen olisi toivonut kohennuksia ennen markkinoille rientämistä. Tietolaatikot, yhteensä peräti 29 kappaletta, ovat osin hauskoja. Esimerkiksi dosentuurien perustamista esittelevässä tietoiskussa kerrotaan, että Turun Akatemiassa innovoitiin Ruotsin valtakuntaan tuo uusi opettajakategoria.

Lukija kuitenkin hyötyisi, jos tietolaatikoita olisi koostettu harkitusti ja ne olisi luetteloitu sivunumeroin. Eriyttäviä elementtejä on kirjassa runsaasti: yksi Suomen korkeakoululaitoksen vuoden 2016 toimipistekartta, 16 taulukkoa, seitsemän kuviota, yhdeksän kuvaa ja yksi asetelma. Liitteitä on kolme, ja henkilöhakemisto mainitaan sisällysluettelossa, mutta asiasanahakemistoa ei ole. Lähdeluettelosta puuttuu useita tekstissä mainittuja viitteitä. Korkeakoulututkimuksen professorin 1998 syntynyttä kirjaideaa olisi toivonut amor sciendi-hengessä vielä hengessä vielä kehitellymmäksi. Kiireisyyden apologia kääntyy esipuheessa yliopistopoliittiseksi moitteeksi.
HISTORIALLISET KERROSTUMAT LÄPIVALAISUSSA

Teos tarjoaa kohtuullisen mittaisia yleiskuvauksia esimerkiksi keskiaikaisesta yliopistolaitoksesta, sen muodostumisesta Ruotsin valtakuntaan ja Turkuun, yliopistolaitoksen organisoitumisesta yhä laaja-alaisemmaksi ja sosiaalisesti kattavavammaksi korkeakoululaitokseksi autonomian ajalla ja korkeakoululaitoksen ja korkeakoulupolitiikan kehityksestä itsenäisyyden ajan alusta 2010-luvulle.

Tekijä tavoittelee myös vaativampaa esitystä, jonka älyllinen haaste on "selittää, miten korkeakoulutus on muuttunut osana yhteiskuntaa" (s.14). Tavoitteeseen hän pyrkii arkeologin tavoin tunnistamalla lähes tuhannen vuoden ajalta "historiallisia kerrostumia", jotka avaisivat korkeakoulutuksen ja sen yhteiskunnallisen ympäristön rinnakkaista kehitystä.

Esteeksi osoittautuu yhteiskuntakehitystä jäsentävän optiikan heikkous. Kirja ei ole koulutuksen historiallista sosiologiaa eikä teoreettista historiankirjoitusta, vaikka joitakin sosiologisia käsitteitä nostetaan paikoitellen avuksi kirjan loppupuolella.

Yhteiskuntakehityksen teorian ja sosiologian yleisen teorian informoiman käsitteistön tuki puuttuvat.

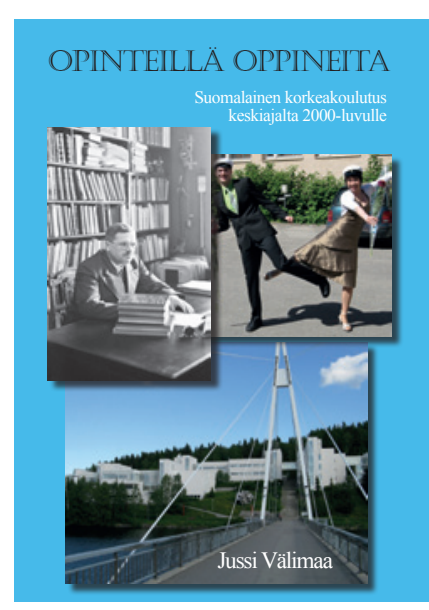

Seuraukset ilmenevät jäsentymättömyytenä ja ratkaisuina, kuten termi 'koululaitosjärjestelmä' luvussa, joka kattaa jakson reformaatiosta Ruotsin vallan loppuun.

\section{KÄSITTEET JÄÄVÄT EPÄSELVIKSI}

Teoksen loppupuolella tekijä toteaa esityksensä olleen lähinnä organisatorista kehitystä kronologisesti kuvailevaa, minkä jälkeen näkökulma vaihtuu temaattiseksi. Päätösluku ”Korkeakoulutuksen instituution ja organisaation kerrostumista” ei kuitenkaan riittävästi selvennä, kuinka organisaation ja instituution näkökulmat eroavat kuvattaessa kehitystä keskiaikaisesta yliopistolaitoksesta nykysuomalaiseen korkeakoululaitokseen.

Keskeisiä käsitteitä ei selvennä johdantojaksokaan. Siinä kerrotaan yliopistosta poliittisena organisaationa ja instituutiona, joka postuloi politiikan yliopiston yhteiskunnallisen ympäristön keskiöön. Esitys ei kuitenkaan ole 
yliopiston poliittista historiaa. Välillä kirjoittaja ulottaa katseensa yhteiskunnalliseen ympäristöön poliittisten kytkentöjen ulkopuolelle, välillä hän taas palaa poliittisen vallan keskeisyyden oletukseen. Historiallisten kerrostumien otsikointi ilmentää poliittisten kytkentöjen kiteytyksen pulmia.

Nykyaikaa lähestyttäessä yhteiskuntaympäristön monimuotoisuus tulee käsitteellisesti vielä hankalammaksi, ja niinpä näkökulmaa kavennetaan korkeakoulupolitiikan kerrostumiin Suomessa 1950-luvulta 1980-luvulle. Kun korkeakoulupoliittiset ohjelmat ja reformipyrkimykset tuodaan tarkasteluun, nyky-yhteiskunnan korkeakoululaitoksen ja korkeakoulutuksen muutos osana yhteiskunnallistumista rajautuu kovin kapeasti, eikä edetä politiikan, joukkoviestinnän, talouden, juridiikan, koulutuksen, tieteen- ja teknologian keskinäisriippuvuuksien analyysissa.

Lopulta kirjoittaja luo katsauksen korkeakoulutuksen "ikuisiin ongelmiin", jotka ovat nousseet esiin "läpi yliopistojen historian”. Ongelmamuodon historialliset kerrostumaerot eivät ole ilmeisesti kiinnostavia.

\section{KOULUTUKSEN POLIITTISET KONTEKSTIT KAIPAAVAT AVAAMISTA}

Toki korkeimman opinnollisuuden, studiumin, kehityshistoriaa keskiaikaisista järjestelyistä alkaen kannattaa kuvata painottuneesti politiikankin kautta, sillä kahden sfäärin, sacerdotiumin ja regnumin, suhde muodostui keskeiseksi dilemmaksi, kun latinalainen sacerdotium sul- keutui imperiumin suojelukseen. Liitossa tarvittiin teologista teoriaa, kanonisen ja roomalaisen oikeuden systematisointia. Näiden ohella studium laajensi yhteiskunnallisuuden alaansa, muun muassa islamisteilta vuonna 1085 takaisin vallatun Toledon arabiankielisten tekstien romaanisten ja latinalaisten käännöskoulujen tuella.

Varhainen yliopistolaitos kolmantena universaalina mahtina paavin (auctoritas) ja keisarin (potestas) vastakohta-asetelmassa oli vailla omaa, yksin sille ominaista, institutionaalista asiasisältöä ja itsenäistä suhdetta Pyhään saksalais-roomalaiseen keisarikuntaan (Reich). Kirkon apulaisena yliopistolaitos oli viime kädessä alisteinen paaville, mutta uutena universaalina organisaatiotodellisuutena se saattoi kasvatuksen ja opin kytkennässään ylittää paikallisen piispan kontrollipyrkimykset. Yliopistoja ei myöskään perustettu keisarikunnassa - vuoteen 1806 asti - minne tahansa, vaan herttuan rankin vaaliruhtinaiden (Kurfürsten) alueille ja erityisin oikeuksin varustettuihin kaupunkeihin (Reichsstädte) (ks. Stichweh 1991, 16-19).

Vallan institutionaalisesta näkökulmasta lähtevän varhaisen yliopistokoulutuksen analyysin olisi kannattanut syventäen avata Pyhän saksalais-roomalaisen keisarikunnan yliopistolaitokselle hedelmällistä poliittista kontekstia. Alueen kehitys on keskeistä, jos Välimaan tavoin kuvaa nykyisyydestä käsin "suomalaisten" opinteiden ja korkeakoululaitoksen genesistä.

Opinnollisuuden juuristo oli teologian tukemaa reformaatiota monisyisempi myös Ruotsin valtakuntaan perustetun Turun Akatemian taustalla. Tieteenhistoriallisen näkökulman ohuus ei auta lukijaa muodostamaan tarkennettua kuvaa varhaisesta ruotsalaisesta yliopistolaitoksesta. Autonomian ajalta esitetään joitain tieteen kehitystä koskevia huomioita, ja kirjan lopussa liikutaan tieteentutkimuksen suuntaan, kun esitellään korkeakoulututkija Tony Becherin kehittämä tieteenalakulttuurien disciplinary cultures -erottelu ja keskustellaan pikaisesti 'akateemisen työn kentistä', eli pätkätyön ja vakivirkojen kentistä.

Jussi Välimaa operoi akateemisesti sekä historiantutkimuksen että korkeakoulututkimuksen piireissä, jotka yhdistyvät ensisijaisesti oppilaitoshistoriallisessa otteessa. Oppilaitoshistorian ja koulutuksen yhteiskunnallisen ilmiön tutkimuksen epäselvä käsitteellinen päällekkäisyys ei ole eduksi. "Korkeakoulututkimus kohdistuu kaikkiin kolmannen asteen oppilaitoksiin [--], sillä korkeakoulututkimusta määrittää sen tutkimuskohde: korkeakoulutus sosiaalisena ja yhteiskunnallisena ilmiönä”.

Yhteiskunnan ajattelun teoreettisin välinein kirjan jäsentely saattaisi kohentua.

\section{KARI KANTASALMI}

FT, koulutuspolitiikan dosentti, tutkimuskoordinaattori Koulutuksen arviointikeskus CEA kasvatustieteellinen tiedekunta

\section{LÄHTEET:}

Stichweh, R. (1991). Der frühmoderne Staat und die europäische Universität: Zur Interaktion von Politik und Erziehungssystem im Prozess ihrer Ausdifferenzierung (16.-18. Jahrhundert). Frankfurt am Main: Suhrkamp. 